\title{
Las redes intelectuales rioplatenses de la médica uruguaya Paulina Luisi: otra cara del internacionalismo feminista del Novecientos
}

The intellectual networks from Rio de la Plata of the UruGUAYAN DOCTOR PAUlina LUISI: ANOTHER FACE OF THE FEMINIST INTERNATIONALISM OF THE NINETEENTH CENTURY

\author{
Inés Cuadro Cawen \\ Universidad de la República, Montevideo, Uruguay \\ http://orcid.org/0000-0002-1839-7224 \\ elines28@gmail.com
}

Resumen: Este artículo estudia el internacionalismo feminista uruguayo de las primeras décadas del siglo XX, a través del análisis de las "redes intelectuales" que forjó la médica Paulina Luisi. En particular, a partir de su vínculo con varias de las líderes universitarias del feminismo argentino. Para ello nos adentramos en la correspondencia privada de Luisi con estas mujeres. Las cartas que recibió nos revelan la existencia de temas y preocupaciones comunes que atravesaron las fronteras estatales y las llevaron a emprender acciones conjuntas. Por ejemplo, campañas a favor de la abolición/ prohibición de la prostitución, de una moral única para ambos sexos o el impulso al "higienismo social" y a la eugenesia. Pero también dan cuenta de las discrepancias que tuvieron sobre cuáles debían ser las estrategias a seguir para concretar sus aspiraciones feministas. Discrepancias, que, teñidas de recelos personales, obstaculizaron la concreción de los mismos.

Palabras Clave: feminismo, sufragismo, internacionalismo, redes intelectuales, historia rioplatense. 
AвSTRACT: This article looks into the Uruguayan feminist internationalism of the early decades of the 20th century through the analysis of the "intellectual networks" forged by doctor Paulina Luisi. It particularly follows her contacts with several other academic leaders of the Argentine feminist movement. To do so, we focus on Luisi's private correspondence with these women. Those letters reveal how their common issues and concerns crossed State borders and led them to undertake joint action, including campaigns supporting the ban on prostitution, equal ethics for both sexes, or the "social hygiene" movement. But they also show their disagreements about the strategies to be followed in order to achieve their feminist goals. Those discrepancies, tainted with personal misgivings, eventually stood in the way of the achievement of their goals.

KeYwords: feminism, suffragist movement, internationalism, intellectual networks, history of the River Plate's region.

\section{INTRODUCCIÓN}

Durante el segundo decenio del siglo XX surgieron en Uruguay organizaciones de mujeres que se autodefinieron como feministas y que se incorporaron a asociaciones internacionales vinculadas al feminismo liberal. Fue un feminismo secular que se orientó, entre otros temas, a la reivindicación de la igualdad en los derechos civiles y políticos, a la mejora en los niveles educativos y profesionales, a la igualdad en materia de condiciones laborales y salariales, a una moral única para ambos sexos y a la paz entre los Estados y al interior de estos. El internacionalismo constituyó una de las características más sobresalientes de la cultura política feminista. Como sostiene Miyares, la búsqueda de igualdad y libertad trascendió a su lugar de emergencia porque los mecanismos de exclusión fueron similares en todas las sociedades. En ese sentido, el internacionalismo feminista se propuso "denunciar singularidades que hay que erradicar independientemente de nacionalidades, credos religiosos y cultural[es]" (200). Para eso se dotó de programas, demandas, estructuras organizativas trasnacionales y se expresó en congresos, asociaciones y en una densa red informal de contactos entre mujeres de diferentes naciones y culturas. Aspectos que han estudiado, desde distintas 
perspectivas, Marino, Threlked, Lavrin, Ehrick, Rupp y Miller. En esta investigación usamos la expresión "internacionalismo" feminista para designar las interacciones entre activistas feministas de diversos países, a través de las organizaciones que se formaron para tales fines y de sus vínculos personales, y que permitieron tejer una red de contactos que cruzaban fronteras (DuBois y Oliviero 2). En particular, nos interesa adentrarnos en este último aspecto, que dadas sus características podemos tratar como una "red intelectual" de mujeres y varones.

Eduardo Devés Valdés define a una "red intelectual" como "el conjunto de personas ocupadas en los quehaceres del intelecto que se contactan, se conocen, intercambian trabajos, se escriben, elaboran proyectos comunes, mejoran los canales de comunicación y, sobre todo, establecen lazos de confianza recíproca" (30). Por otra parte, el concepto de red permite dar cuenta de que estos vínculos personales no eran unilaterales, sino que estaban integrados en un entramado de relaciones que los dotaban de sentido e intencionalidad. Además, eran conexiones que se llevaban a cabo en un plano de horizontalidad, en el que primaba la influencia recíproca, y que contribuyeron a generar una conciencia feminista que trascendía las fronteras nacionales.

El destacar una parte de la correspondencia de la médica socialista Paulina Luisi (1875-1950) da cuenta de lo prolíferos que fueron sus intercambios epistolares y las "redes intelectuales" que construyó. Además, revela que detrás de los formalismos institucionales había una amplia gama de vínculos personales, de amistad o no, que favorecían u obstaculizaban los emprendimientos conjuntos. En esta investigación hemos optado por detenernos en sus vínculos con las feministas argentinas y en algunos de los temas/debates que nutrían sus intercambios. No obstante, cabe señalar que Luisi entabló vínculos estrechos también con feministas españolas, cubanas, chilenas y mexicanas.

La relevancia de Paulina Luisi como líder del movimiento feminista liberal uruguayo y su larga trayectoria en el escenario internacional hacen de su archivo una base de información fundamental para los objetivos de esta investigación. Su análisis nos permite, justamente, reconstruir las redes trasnacionales que la médica uruguaya forjó por más de cuatro décadas. Pero trabajar con correspondencia privada requiere tener ciertos recaudos sobre la pertinencia de revelar información que los sujetos históricos con los que se está trabajando dejaron en el plano íntimo. Las 
autoras de las cartas que analizamos no supusieron su exposición pública. Esto, por otra parte, en palabras del historiador José Pedro Barrán, "acrecienta su carga de sinceridad y su valor testimonial" (Barrán 15). En efecto, la correspondencia personal enriquece el análisis histórico y complejiza este pasado que estamos estudiando, permitiendo reducir la escala de observación al nivel de los sujetos y sus vínculos personales. A través de ella nos adentramos en las emociones, los recelos, las envidias, los egos y los amores: otros factores causales que una investigación histórica ha de tener en cuenta. Además, en el caso de las mujeres, las cartas ayudaron a "gestionar emociones reprimidas, o desterradas, de los espacios de la sociabilidad cara a cara” (Peluffo 142). Esto hace de estas fuentes un registro del pasado cargado de espontaneidad, pero también de subjetividad. Aspectos que deben estar presentes al momento de analizar este epistolario.

\section{Paulina Luisi: a un lado y Otro del Plata}

Paulina Luisi nació en Colón, en la provincia argentina de Entre Ríos, en 1875. Su padre, Ángel Luisi, era italiano, liberal masón y legionario garibaldino y su madre, María Teresa Janicki, era de origen polaco pero natural de Francia y se desempeńó como maestra e inspectora en un instituto educativo de la ciudad de Dijon, donde se involucró en las primeras campañas a favor del voto femenino. El matrimonio llegó a la Argentina en la década de 1870 y pocos años después decidió cruzar el río Uruguay para instalarse en la ciudad uruguaya de Paysandú. Allí, la pareja se dedicó al magisterio desde una pedagogía liberal y racionalista, valores e ideología que trasmitieron a sus seis hijas y dos hijos. Motivada por ese clima familiar liberal y progresista para la sociedad uruguaya, Paulina estudió magisterio y luego, en 1900, ingresó a la universidad para estudiar Medicina. Fue la primera mujer en graduarse de doctor en Medicina y Cirugía en 1908, y con ello siendo también la primera en recibir un título universitario en el país.

$\mathrm{Al}$ recibirse, comenzó a trabajar en un consultorio particular en el centro de la ciudad, en el Hospital Maciel y en la Clínica de Ginecología de la Facultad de Medicina. Pero, al igual que muchas de las primeras universitarias de la región y de Europa, además de dedicarse a su pro- 
fesión, comenzó a militar en pro de los derechos civiles y políticos de las mujeres. En este sentido, fue por iniciativa de ella que se fundaron en Uruguay las dos primeras organizaciones feministas de carácter internacional: el Consejo Nacional de Mujeres y la Alianza Uruguaya para el Sufragio Femenino. Desde estas organizaciones, además de interesarse en los derechos políticos, Luisi mostró espacial preocupación por el tema de la prostitución -ya vinculada a ella la educación sexual y la profilaxis-. De ahí que, en la década del veinte, presidiera la Comisión Internacional contra la trata de mujeres y una moral única de la International Woman Suffrage Alliance, fuese fundadora y secretaria general del Comité Abolicionista Argentino-Uruguayo contra la trata de mujeres y la reglamentación de la prostitución, así como miembro honorario de la Liga Chilena de Higiene Social. También organizó múltiples campañas contra la prostitución reglamentada en el Río de la Plata, especialmente en Buenos Aires. Escribió una serie de folletos sobre este asunto, una serie de trabajos sobre enseñanza sexual y dictó un número importante de conferencias sobre estos temas en América y en Europa. Integró también la Comisión de Expertos sobre Trata de Mujeres en la Sociedad de Naciones. Su presencia destacada en eventos y comisiones internacionales le permitió generar una amplia red de vínculos personales con mujeres y varones que eran afines a su ideología.

En la década de 1930, su espíritu pacifista y sus ideas socialistas la llevaron a sumarse a los opositores del fascismo europeo. Integró varias sociedades pacifistas y durante la Guerra Civil española estuvo implicada en planes de ayuda material y moral a la república. Murió en Montevideo en 1950, a los 75 años de edad, con una trayectoria política, profesional y de vida extraordinaria para cualquier época ${ }^{1}$.

La historiadora estadounidense Christine Ehrick, que se ha detenido en el estudio del feminismo liberal uruguayo, destaca la influencia que ejerció el movimiento feminista argentino en Uruguay a partir del análisis de la correspondencia de Luisi con algunas feministas argentinas. Para esta historiadora, el contexto político-social uruguayo contribuyó a fortalecer al feminismo liberal e incluso le permitió crecer más que el argentino, sin olvidar que Argentina fue pionera en materia de asociacionismo feminista en América del Sur, motivo por el cual el vinculo

Los datos biográficos fueron extraídos de (Scarone; Sapriza; Lavrin; López; Ehrick). 
iniciático de Luisi con las universitarias argentinas le permitió seguir su ejemplo y evitar sus errores. Al respecto, son destacables los consejos de algunas feministas argentinas que le recomendaron evitar que en el Consejo Nacional de Mujeres (CNM) uruguayo concentraran el poder las mujeres de la élite vinculadas a la beneficencia, como sí había sucedido en el argentino (Vignoli 122).

No obstante, Ehrick considera que la relación con Argentina fue compleja y por momentos el nacionalismo generó rispideces. Desde su perspectiva, si para las mexicanas o las cubanas sus problemas eran con las feministas de los Estados Unidos, para las uruguayas la mayor amenaza tenía sede en Buenos Aires. Esta afirmación se sustenta sobre todo en una carta de Paulina Luisi a la feminista mexicana Elena Arizmendi. En ella, Luisi le comenta que el III Congreso Internacional Femenino, celebrado en Buenos Aires, fue "extraordinariamente nacionalista, casi diría, Argentina. Esto no es sorpresa, Argentina es una nación grande, se siente fuerte e independiente, no solo políticamente sino económicamente; serán los yanquis del Sur" (cit. en Erhick 412).

Si bien estas palabras pueden interpretarse como una crítica al carácter "imperialista" que podía asumir Argentina en la región, no parece que entre las mujeres haya primado el nacionalismo en sus vínculos con el país vecino. Menos aún en Luisi, quien se definía como "hija de ambas naciones": de una por nacimiento -recordemos que había nacido en la Provincia de Entre Ríos- y de la otra por su formación. Por otra parte, una de las características más sobresalientes del feminismo argentino fue su heterogeneidad ideológica, con la consiguiente convivencia de múltiples asociaciones femeninas y muchas de ellas rivales. Luisi se incorporó y participó en la fundación de varias de estas asociaciones, construyendo una importante red de vínculos con las principales referentes del feminismo liberal y socialista argentino. Con otras, por el contrario, tuvo sus diferencias, como con el CNM de Argentina o la Unión Feminista Nacional. De ahí que resulte más adecuado referir a asociaciones puntuales que al feminismo argentino en general.

De acuerdo con la metodología propuesta por Devés Valdés, para identificar una "red intelectual" es necesario tener en cuenta los contactos cara a cara, la correspondencia epistolar, la participación en los mismos congresos, asociaciones, comisiones y campañas, las publicaciones conjuntas, las referencias recíprocas en los artículos que escribían, el envío 
de libros, revistas y periódicos, así como la densidad y prolongación en el tiempo de las comunicaciones (30) Teniendo en cuenta estos aspectos, es adecuado señalar que Luisi formó una "red intelectual" con las argentinas Petrona Eyle, Alicia Moreau, Sara Justo, Elvira Rawson de Dellepiane, Julieta Lanteri y Blanca Colt de Hume, la mayoría de ellas universitarias. Estos vínculos comenzaron siendo profesionales, exceptuando a Blanca Colt de Hume, y se estrecharon aún más al compartir una causa común: mejorar las condiciones jurídicas y de vida de las mujeres. Con todas ellas compartió el Congreso Internacional Femenino de 1910 y con algunas, tres años después, el Primer Congreso del Niño, que se celebró también en Buenos Aires. Claro que la cantidad de emprendimientos en conjunto, la frecuencia en la comunicación y el grado de intimidad compartida en sus cartas evidencian que con varias también construyó un vínculo de amistad, aunque con distintos grados de profundidad y de continuidad en el tiempo.

\section{HigiENe SOCIAL, EUGENESIA Y ABOLICIONISMO}

Uno de los temas que concitó la atención de Paulina Luisi desde que se recibió como médica fue la "higiene social", un área de la medicina que emergió con fuerza a comienzos del siglo XX y que refería al estudio de la influencia que ciertas condiciones sociales y laborales tenían sobre la salud de la población, así como a las medidas sanitarias necesarias para frenar o disminuir las influencias nocivas. De modo que, en la época, la higiene social comprendía aspectos vinculados a la moralidad, la profilaxis, la sexualidad, la prostitución, la trata de mujeres y otros "vicios sociales" como el alcoholismo.

En sus primeras participaciones en congresos internacionales y regionales, Luisi se adentró en estas cuestiones, demostrando que eran una de sus principales áreas de interés médico y social. Estos temas también la llevaron a convertirse en un referente académico de impacto internacional y sobre los cuales construiría una de sus redes intelectuales más importantes. En este sentido, Luisi emergió como uno de los exponentes más connotados en la región sobre los estudios eugenésicos. De acuerdo con la historiadora uruguaya Graciela Sapriza, la eugenesia fue un área de estudio científico que en los años veinte despertó entusiasmo entre varias 
figuras destacadas de la región. "En Sudamérica predominó la versión latina, del francés Jean-Baptiste Lamarck, que sustentaba la trasmisión de los caracteres adquiridos, lo que permitía dar importancia al medio ambiente tanto como a la herencia genética" (Sapriza 889). Esta visión de la eugenesia se apoyaba en el convencimiento de que por medio del control de la sexualidad, las mejoras en las condiciones materiales de vida y la supresión de los vicios sociales, se garantizaría una "buena natalidad" que contribuiría al mejoramiento de la "raza".

Varias médicas rioplatenses y feministas miraron con optimismo los postulados de esta "nueva ciencia". A nivel gubernamental, con la influencia de estas profesionales se llevaron a cabo varias políticas de salud, de inmigración, de protección a la infancia y la maternidad, entre otras. En 1911, algunas de esas médicas, Paulina incluida, fundaron la Liga de los Derechos de la Mujer y el Niño y luego, en 1916, organizaron el Primer Congreso Americano del Niño en Buenos Aires. En su participación, Luisi expuso algunas de sus ideas más controversiales de inspiración eugenésica, como "esterilizar a los individuos con problemas genéticos o mentales y permitir el aborto a aquellas mujeres casadas que hubiesen resultado embrazadas por el coito forzado con su marido" (cit. en Guy 115). Probablemente no haya escandalizado tanto la propuesta de esterilización como la de sugerir la posibilidad de que las mujeres decidieran sobre continuar o no un embarazo y más aún la denuncia de violación dentro del matrimonio. No obstante, este pronunciamiento de Luisi a favor de algún tipo de "esterilización" evidencia que la dicotomía eugenesia latina/anglosajona -la primera positiva, en tanto promovía mandatos legales y morales que mejoraran la composición de la población, y la segunda negativa, por su determinismo genético que conllevaba medidas radicales como la esterilización y la eutanasia- fue más porosa de lo que la producción historiográfica sobre el tema ha destacado ${ }^{2}$.

Tres años después, se realizó el Segundo Congreso Americano del Niño en Montevideo. En esa oportunidad, la propuesta de Luisi apuntó a una serie de reformas sociales y legales que permitieran lograr los resultados prácticos que la eugenesia suponía. Estas reformas contribuirían a la emancipación sexual femenina y a la protección de la madre y el hijo. Luisi proponía que se estableciera una única moral para ambos sexos y que la maternidad fuese concebida e instituida como "función del

2 Para mayor detalle, véase (Leys Stepan; Miranda y Vallejo). 
Estado": "siendo por lo tanto una obligación de la Nación la defensa y protección económica, moral y legal de toda mujer en el desempeño de sus funciones naturales de la maternidad" (Luisi, "Conclusiones" 92). Esto implicaba prever que en la Administración Pública existiese una repartición que concretara ese apoyo económico. Se tenía que reconocer, además, a "la mujer como jefe directo de la familia -en otros términos sobre la base de un matriarcado-; obedeciendo así al siguiente axioma derivado de los derechos naturales, los hijos pertenecen en primer término a la madre" (ibid.). Estas afirmaciones eran doblemente desafiantes para la época. Por un lado, iban un paso más allá en materia de derechos civiles respecto a la igualdad de los sexos, al anteponer el derecho de la madre sobre los hijos; y, por otro, convertían el valor reproductivo de la mujer en un valor productivo para el Estado y, por ende, lo hacían plausible de ser remunerado.

Una de las médicas argentinas pioneras en adentrarse en los estudios eugenésicos fue Petrona Eyle (1866-1945), quien realizó sus estudios de medicina en Suiza, de donde era originaria su familia. Eyle se recibió en 1891 con una tesis en alemán sobre los caracteres físicos de los delincuentes. Con ella, Paulina Luisi entabló uno de sus primeros vínculos profesionales en la Argentina, el que se extendió por más de dos décadas y con el devenir del tiempo se convirtió en uno de sus más íntimos. El intercambio epistolar comenzó en 1907, un poco antes de que Paulina se recibiera de médica. Petrona la invitó a formar parte de la Asociación de Universitarias Argentinas que ella misma había fundado en 1904. En sus primeras cartas priman los temas médicos. Eyle era nueve años mayor que Luisi y tenía más de quince ańos ejerciendo la medicina, por lo cual solía darle consejos sobre la profesión. Por ejemplo, le explica que "si te decides a asistir partos, luego asistirás a esos niños, pero clientela de niños como tu deseas creo que será difícil la obtengas. Hasta ahora todas las médicas que conozco aquí como en Europa tienen más bien clientes mujeres" (BNAL-FPL, Eyle a Luisi, 14.05.1908).

A partir de 1910, cuando ambas participan del Primer Congreso Internacional Femenino que se celebró en Buenos Aires con motivo de los festejos del Centenario de la Revolución de Mayo, Luisi como corresponsal en Uruguay y Eyle como presidenta del Comité Organizador, comenzaron a referir en su relación epistolar a cuestiones de política y feminismo. Para fines de la década, sobre todo en 1919, la correspon- 
dencia era casi semanal y reflejaba un vínculo de amistad muy cercano. Tal es así, que ese año Paulina fue sometida a una cirugía y Eyle viajó a Montevideo para cuidarla en el sanatorio. También por esos años, la militancia feminista se acrecentó en ambas. Luisi presidía el CNM de Uruguay y la Alianza Uruguaya para el Sufragio Femenino. Eyle, en tanto, integraba la Unión Feminista Nacional que había fundado Alicia Moreau en 1918 y dirigía su revista Nuestra Causa -desde su creación hasta marzo de 1920-, formaba parte del Partido Feminista Nacional, de la Asociación Pro Derecho de la Mujer y presidía la Asociación Argentina contra la Trata de Blancas.

Otro espacio que comparten en 1920 es el Comité Femenino de Higiene Social. Este se creó a iniciativa de la escritora Blanca Colt de Hume en el marco del Comité Argentino-Uruguayo de la Federación Abolicionista Internacional, fundado un año antes por Paulina Luisi y Ángel Giménez. Su principal objetivo era avanzar en las campañas abolicionistas que permitieran terminar con la prostitución reglamentada y, junto con ello, educar en una moral única para ambos sexos. Al detenernos en quienes integraron el Comité Femenino de Higiene Social, evidenciamos que los vínculos de Luisi en Argentina conformaron una red, pues en él confluyeron Petrona Eyle -que actuó como secretaria-, Alicia Moreau, Sara Justo, Elvira Rawson de Dellepiane, Julieta Lanteri y Paulina Luisi. En efecto, todas compartían la militancia a favor de la abolición de la prostitución, la lucha contra la trata de mujeres, y, vinculado a ello, la promoción de la "higiene social" y la "moral única". Pero en otros aspectos diferían, sobre todo en cómo llevar adelante la acción feminista. Eso explica las múltiples asociaciones feministas que algunas de ellas presidieron: Alicia Moreau fundó la Unión Feminista Nacional, Elvira Rawson de Dellepiane, la Asociación Pro Derechos de la Mujer -de la cual Blanca Colt de Hume fue secretaria ${ }^{3}$ - y Julieta Lanteri, el Partido Nacional Feminista. Petrona Eyle formó parte de las tres asociaciones y Luisi también estuvo adherida o fue invitada a dictar conferencias en todas ellas. Todas, a su vez, publicaron en Nuestra Causa, revista de la Unión Feminista Nacional, así como en la efímera Nosotras, revista del Comité Pro Derechos de la Mujer que sacó un solo número, y en Acción Femenina, la revista del CNM de Uruguay. En sus

3 Para 1921 figura como secretaria la periodista Adelia Di Carlo, amiga de Blanca Colt de Hume, y que años después representará a Argentina en la Liga Internacional de Mujeres Ibéricas e Hispanoamericanas. 
correspondencias solían aludir a los artículos o recortes de prensa-que acompañaban las misivas- sobre temas que podían interesarles o que referían a la labor puntual de alguna de ellas.

El intercambio epistolar entre Paulina Luisi y la escritora Blanca Colt de Hume fue muy intenso entre 1919 y 1920, cuando se formó el Comité Femenino de Higiene Social. Blanca Colt de Hume le enviaba reportes detallados de sus esfuerzos por conseguir nuevas adhesiones al comité que presidía. Su principal interés era llegar a las mujeres más “conservadoras". En ese afán, le sugiere a Luisi

Insistir más sobre la educación e higiene moral que sobre la abolición de la reglamentación, ya que pocas parecen entender este asunto, creyendo que abolir la reglamentación sería dar rienda suelta al vicio... Yo creo que debemos relacionar la campańa moralizadora con la salud y felicidad de los hijos, que es lo que a la mayoría le interesará, si no me equivoco (BNAL-FPL, Colet a Luisi, 20.10.19).

En otra oportunidad, le propuso que, en lugar de hablar de educación sexual en los niños, era mejor utilizar la expresión "educación moral". Blanca Colt de Hume parecía conocer bien el ambiente femenino porteño y las sospechas que podía generar cierto vocabulario. Tanto es así, que, cuando el CNM argentino invitó a Paulina Luisi a dar una conferencia y se enteró de que hablaría sobre prostitución, terminó desestimando su intervención. Luisi aludirá irónicamente a ello muchos años después, al recordar que la presidenta del CNM argentino había expresado que "las mujeres honestas no deberían permitir que se hablase delante de ellas de cosas tan inmorales como la lucha contra la prostitución". Agregando: "ingenuamente yo iba a invitarla a una conferencia que iba a dar contra la prostitución reglamentada. Fue así como me di cuenta de mi inmoralidad... en la que continúo reincidiendo" (Luisi, "A las mujeres" 28).

En diversas cartas, Blanca Colt de Hume hace alusión a la importancia que podría tener para el comité que se incorporará la médica socialista Alicia Moreau. Si bien Luisi mantuvo un vínculo muy cercano con ella entre 1910 y 1920, también hubo mucha rivalidad. Ambas eran socialistas, médicas, feministas y contaban con cierta 
proyección internacional. En 1919, emprendieron una gira por Córdoba para dar una serie de conferencias sobre feminismo e higiene social. La preparación del viaje hizo que la comunicación entre ambas fuese más intensa ese año. Pero al año siguiente, por motivos varios, la comunicación fue mínima y, por la correspondencia de Luisi con otras mujeres del entorno feminista porteño, podemos deducir que ese distanciamiento fue intencional por parte de la médica uruguaya. Uno de los motivos que pudo haber incidido fue el rechazo de Moreau a integrar el Comité Abolicionista Argentino-Uruguayo que fundaron Luisi y el doctor Giménez en 1919. Más aún si un año después fue invitada al Congreso Internacional de Médicas, realizado en Nueva York, y presentó un trabajo sobre prostitución y educación sexual, afín con las ideas abolicionistas. Por otra parte, la visita de Moreau a los Estados Unidos le permitió tomar contacto directo con el movimiento feminista de aquel país, que a ojos de algunas feministas liberales y socialistas rioplatenses estaba cargado de una peligrosa moralidad religiosa. A Moreau también molestó la elección discrecional para ese congreso, siendo la única representante rioplatense. Para Luisi, el deseo de Moreau de formar parte del Comité Femenino de Higiene Social a su regreso de los EE. UU. se sustentaba en su deseo de "figurar" y no tanto en un interés real con la causa abolicionista. De ahí el malestar que le provocó que terminara integrándolo.

Respecto a estas cuestiones sobre abolicionismo, higiene social y eugenesia, Luisi encontró en la orilla vecina un grupo de mujeres afines con su pensamiento y militancia. Fueron en su mayoría médicas, como ella, lo cual las convertía en interlocutoras válidas, incluso entre los varones, por el peso que representaba su profesión. Luisi emergió como una especialista en el tema a nivel internacional, pero representaba a un país y a un continente mayoritariamente reglamentaristas. De ahí que sus vínculos personales fueran fundamentales para contrarrestar las resistencias gubernamentales a legislar y a poner en la agenda pública esta problemática social, económica y moral. Por otra parte, los debates y proyectos que concitaron su atención refuerzan los planteos en torno a cómo el feminismo maternal atravesó a todas las organizaciones feministas de entonces. Las feministas rioplatenses, como sostiene la historiadora argentina Marcela Nari, "intentaron reformular la maternidad como una función social y política, pero sin abandonar la idea de la naturaleza maternal femenina" (300). 


\section{SUFRAGISMO Y FEMINISMO}

“¿Usted no se ocupa de política? Yo sí, yo soy politiquera 'enrage’. Pero no digo nada, muy librepensadora, quiero el sufragio para las mujeres, pero me callo la boca, porque aquí no hay oídos para esas cosas" (BNALFPL, Eyle a Luisi, 9.12.1907). Estas palabras de Eyle a Luisi, pocos meses después de haber comenzado su vínculo epistolar en 1907, reflejan el frustrado silencio que debían guardar muchas mujeres ilustradas. Pero también cómo supieron canalizarlo a través de sus vínculos privados, pues en sus cartas proliferan análisis, opiniones y reflexiones sobre el acontecer político nacional, regional e internacional.

Este aspecto fue particularmente evidente en la correspondencia entre Paulina Luisi y Alicia Moreau. Alicia actuó para Paulina, en ocasiones, como un nexo con las figuras más prominentes del Partido Socialista argentino: José Ingenieros, Enrique del Valle Iberlucea y Alfredo Palacios. Por otra parte, el interés de Moreau por la política la llevó a estar muy interiorizada con lo que pasaba en Uruguay, buscando en Luisi una interlocutora válida. Es más, le llegó a decir "créame la estimo mucho. Ud. es de las pocas mujeres que he conocido con espíritu verdaderamente viril, sin la vanidad y superficialidad de tantas mujeres que han estudiado, siendo siempre el mismo animalito pueril, lleno de reclamaciones, gestos y actitudes de supuestas gracias y supuestos atractivos para el otro sexo" (BNAL-FPL, Moreau a Luisi, 8.16). Este pasaje refleja cómo, incluso entre mujeres, las características propias de los hombres (el "espíritu viril”) tenía una valoración más positiva que las atribuidas a las féminas. Parecería que esta impronta masculina era la que las llevaba a interesarse por los asuntos de la política, reforzando con ello una identidad femenina consustanciada a los "asuntos del corazón".

En las cartas que escribió Alicia Moreau a Luisi abundan las alusiones a la política rioplatense. En 1916, por ejemplo, le comenta que había estado hablando con Enrique del Valle "del maquinatrás del gobierno uruguayo”. Y le pregunta: “¡es sincero? Qué lástima que así sea, qué triunfo para los reaccionarios... este ejemplo y muchos otros me convencen cada vez más del valor social de la educación, todos los proyectos, todos los planes, las reformas políticas, nada valen ni pueden si no tienen la base sólida de la educación" (BNAL-FPL, Moreau a Luisi, 8.16). Moreau estaba haciendo referencia al giro político que inició el 
presidente Feliciano Viera, cuando el batllismo perdió las elecciones a la Asamblea Nacional Constituyente, el 30 de julio de 1916. El llamado "Alto de Viera" significó un freno al reformismo en materia social y económica que venía llevando adelante este sector, liderado por José Batlle y Ordóñez, desde hacía una década.

Un año después, Moreau le pregunta a Luisi qué opina de la política uruguaya. Desde la perspectiva de Moreau, la situación para el socialismo uruguayo era más compleja, porque el "partido de Batlle" estaba llevando a cabo reformas sociales y económicas fundamentales, "que por ahora no pueden interesar a la gran masa demasiado ignorante”. En cambio, en Argentina era "más fácil la acción socialista, pues radicales o conservadores [son] todos de la misma tela" (BNAL-FPL, Moreau a Luisi, 30.01.17). La comparación entre un país y otro es frecuente en las cartas de Moreau a Luisi, dejando entrever cierta admiración por el gobierno batllista, pese a que este significara una limitación para el crecimiento del socialismo en Uruguay. Por otra parte, a través de su relación epistolar constatamos la influencia recíproca entre los movimientos feministas a ambos lados del Río de la Plata. Aunque más tardío en su organización, el movimiento feminista uruguayo fue más osado en sus reclamos al gobierno que el argentino. Por ejemplo, en marzo de 1917, el CNM uruguayo envió una carta a la Asamblea Nacional Constituyente solicitando los derechos políticos para las mujeres en la nueva Constitución. La noticia cruzó el río y varias feministas le hicieron llegar sus impresiones a Luisi. Petrona Eyle le expresó que era

indudable que con ese paso, las mujeres uruguayas marchan a la cabeza en la América del Sud, pues no tengo conocimiento que en otro país se halla pedido tal cosa. Cuando uno compara lo que han luchado las inglesas para obtener el voto! De todos modos da gusto ver que las liberales uruguayas han puesto valientemente manos a la obra y les deseo buen éxito en la lucha (BNAL-FPL, Eyle a Luisi, 28.05.1917).

También Alicia Moreau le escribirá al respecto:

felizmente para usted, está en un país abierto a las ideas nuevas, dónde estas si no son aceptadas por todos por lo menos son discutidas [...] Conforme vea a del Valle le comunicaré lo que 
usted ha hecho pues sé que desde hace varios años el desea presentar en el senado un proyecto sobre este punto, solo que con el gobierno reaccionario que tenemos, esto es simplemente incluir las carpetas (BNAL-FPL, Moreau a Luisi, 12.03.17).

En efecto, el 21 de mayo de 1918 Enrique del Valle Iberlucea presentó al Senado argentino un proyecto para la emancipación civil de la mujer. Si bien el mismo contó con un despacho favorable por parte de la comisión de Código del Senado, terminó no siendo considerado en Cámara. Recién en 1926 se logró la aprobación de la primera ley que reconoce igualdad de derechos civiles a las mujeres, tomando como base el proyecto de Del Valle.

Los avances del feminismo uruguayo también serán destacados por la médica feminista Julieta Lanteri, quien en su correspondencia con Luisi dio cuenta de la atención que prestaba -con cierta admiración- a lo que sucedía del otro lado del río. Por ejemplo, en 1921 le menciona:

conozco el proyecto del P. Colorado, preparado por el presidente [Baltasar] Brum. Admirable. He leído [durante las] semanas pasadas muchos números de La Razón, de esa en la cual vi con mucho agrado que se hace una intensa y hermosa campańa periodística en pro del sufragio femenino (BNAL-FPL, Lanteri a Luisi, 22.09.21).

Justamente, las campañas en pro del sufragio femenino fueron una cuestión que se vivió con mucha intensidad entre estas mujeres y que despertó discrepancias -algunas insalvables- sobre cuáles debían ser las estrategias para concretar sus aspiraciones feministas. Los logros obtenidos en materia de derechos políticos por británicas y estadounidenses tras la Gran Guerra marcaron el camino a seguir a las mujeres sudamericanas. Sin embargo, se puso énfasis en que la inclusión de las mujeres en la política era más el resultado de un proceso evolutivo que un acto revolucionario. Para ellas, los cambios moderados -y no las tácticas anglosajonas- se ajustaban mejor a la idiosincrasia local. En 1918, la socialista argentina Alicia Moreau le comentaba a su amiga Paulina Luisi que estaba leyendo un libro sobre los cincuenta ańos de historia de la lucha sufragista inglesa. Esta lectura la llevaba a admirar a las inglesas, porque "con qué energía, con que tesón supieron sostenerse". Pese a la 
admiración que le despertaban, asumía que no sentía esa campaña en su temperamento, ni en las mujeres de aquí. "La campaña feminista entre nosotras", reflexionaba Alicia Moreau, "debe tener y tendrá un carácter distinto al de aquel tan batallador. Tenemos un tacto especial para el ridículo y somos demasiado españoles" (BNAL-FPL, Moreau a Luisi, 27.08.17). En los años veinte, ese sentimiento de identidad en común con las espańolas cimentó la creación de una alianza hispanoamericana que buscó contrarrestar el avance del panamericanismo en la región.

Para algunas feministas rioplatenses, Luisi incluida, el protagonismo asumido por las sufragistas estadounidenses en el asociacionismo feminista internacional les despertaba cierto recelo. Por ejemplo, en 1919, Petrona Eyle le comentaba a Luisi sobre la visita de unas feministas estadounidenses y agregaba:

el mundo será de los ingleses y de los norteamericanos! La Liga de las Naciones amenaza con ser la horca de todos los países que no responden a los míster y a las mises! Verás tu como serán esas dos naciones las que van a imponer su voluntad hasta que los japoneses, chinos y otros colores no les aprieten las clavijas (BNAL-FPL, Eyle a Luisi, s/f 1919).

El final de estas líneas da cuenta, también, de la sagacidad de Eyle para analizar la política internacional de su presente y, lo que sorprende más, respecto a las proyecciones a futuro.

Volviendo a la cuestión de las estrategías para visibilizar los reclamos feministas, nos resulta interesante analizar las diversas reacciones que despertó entre las feministas rioplatenses la forma de proceder de la doctora Julieta Lanteri (1873-1932) -italiana de nacimiento, librepensadora y masona-, quien se convirtió, presumiblemente, en la primera mujer que votó en América Latina. Lanteri atravesó la barrera del espacio público de un modo poco convencional para su época. Forzada a obtener la carta de ciudadanía argentina para poder ejercer como docente universitaria, optó por demostrar la inconsistencia de las leyes y exigir el ejercicio pleno de esa ciudadanía concedida. En efecto, la Constitución argentina nada decía sobre el sexo del ciudadano. Si bien la justicia terminó frenando sus aspiraciones electorales, no solo incursionó en el derecho a voto en 1911, sino que fue más allá y se postuló como candidata a diputada nacional en las elecciones del 23 
de marzo de 1919, por el Partido Feminista Nacional, fundado por la propia Lanteri en 1918. Para dicha elección, contó con el respaldo de la Unión Feminista Nacional, del Comité Pro Derecho del Sufragio Femenino, que presidía Elvira Rawson y de algunos grupos militantes de La Boca, Barracas y Balvanera.

La actuación política de Julieta, como bien sostiene Dora Barrancos, "evidencia una voluntad singularmente determinada, la exhibición de un deseo potente de libertad y la afirmación de una subjetividad soberana que la condujeron a emprendimientos nada convencionales" (113). Tan poco convencionales que, cuando el 14 de marzo de 1919 hizo pública su candidatura, esta incomodó tanto a varones como a mujeres. Su programa recogía postulados del socialismo y del librepensamiento, pero fundamentalmente las reivindicaciones más radicales del feminismo del momento: derecho al voto, horario reducido para las trabajadoras mujeres, salarios iguales, divorcio absoluto, igualdad para los hijos sin distinción de legítimos o no, abolición de la prostitución, entre otros.

Petrona Eyle fue una de las principales aliadas de Julieta y procuró, en su correspondencia con Luisi, defenderla a pesar de que su interlocutora pensara lo contrario:

No pienso como tú que el gesto de Julieta sea perjudicial al feminismo, al contrario, como lo dijo hoy un orador[,] el hecho por ser prematuro será grandemente útil porque ha despertado muchísimo interés y familiarizado al público con esas ideas. Yo te cuento todo esto para que te animes tu hacer lo mismo en tu tierra- Adelante- La propaganda ya la han hecho las inglesas, que tanto dieron que hablar, ahora en los demás países del mundo, ya es juguete en comparación de lo que tuvieron que hacer las inglesas y las americanas. Lo que sí hay que arriesgar algunos pesitos, pues la propaganda cuesta. Julieta ha tenido mucha ayuda gratis, por cierto, no de feministas! Guay las feministas! Envidiosas, pequeñas (BNAL-FPL, Eyle a Luisi, 16.03.1919).

Algunas de las feministas a las que aludía Eyle eran muy cercanas a ella, como Sara Justo, Elvira Rawson de Dellepiane o Alicia Moreau. Por ejemplo, la socialista y universitaria Sara Justo (1870-1941), al día siguiente de que Lanteri presentase su candidatura, le preguntó irónicamente a Luisi si esta era “¡al manicomio o a diputada?”. Luego le contó 
en detalle cómo había sido el evento y le explicitó su disconformidad con la iniciativa:

Pobre Julieta! Que ganas de macanear y hacer daño a la causa. No hay duda, que así y todo tiene un valor y una resistencia de corcho, para que los golpes de la crítica no lo detengan en su propósito; pero ha salido con el gusto de ser la $1^{\circ}$ candidata (de sí misma) de Sudamérica. Tome usted que se creía que tendría ese honor - se ha equivocado (BNAL-FPL, Justo a Luisi, 15.03.1919).

También Alicia Moreau le escribió pocos días después para referirse al tema. En su caso, destacaba la efervescencia política que había generado el "gesto de Lanteri". Y agregaba: "no hay duda que es coraje el suyo, pues sin titubear se expone a una situación que debe saber de antemano enojosa y sin provecho alguno, fuera de la agitación de la opinión". No obstante, a medida que empieza a ver el impacto que la candidatura estaba generando en la opinión pública, concluye que "no podemos decir que sea inútil, ha llamado la atención, ha despertado a la gente; los diarios se han ocupado" (BNAL-FPL, Moreau a Luisi, 15.03.19).

En efecto, la estrategia de Lanteri de entrar en la contienda electoral, aunque no tuvo efecto jurídico, sí interpeló a promotores y adversarios del sufragio femenino. Algunas feministas, incluso, que en un principio habían rechazado la propuesta, un año después, acompañaron al Partido de Lanteri en un simulacro electoral femenino que logró un poco más de cuatro mil votos.

El análisis de las diversas reacciones que generó la candidatura de Lanteri entre sus propias "compañeras" feministas, permite constatar los roces y las disputas personales que se sucedían en el ámbito del asociacionismo feminista. Desde las teorías feministas se han esbozados algunas interpretaciones sobre el porqué de esta rivalidad femenina. Marcela Lagarde sostiene que "la enemistad entre mujeres es el resultado de la organización patriarcal del mundo y es estimulada en la educación y sociabilización de género de las mujeres" (307). En una sociedad jerarquizada a favor del hombre, "las mujeres viven enormes dificultades para identificarse entre ellas, porque en su admiración de lo que no son y de lo que no tienen, en su necesidad del poder, intentan identificarse con el hombre". Desde esta perspectiva, "no se trata de que, por su voluntad, las mujeres se afanen en el desencuentro" (ibid.). Pero este desencuen- 
tro se produce también entre las propias mujeres que comparten un discurso emancipador de género. También conviene tener presente que nos estamos moviendo en el mundo de la correspondencia personal y, como sostiene Ana Peluffo, en el "espacio virtual" de la carta se habilita la "aparición de afectos incómodos (la envidia, los celos, la indignación)" que se reprimen en los contactos presenciales (142).

Por otra parte, cada una de ellas tenía un posicionamiento político-ideológico que antecedía a su identidad feminista e incidía en sus propuestas de acción política y en sus programas reivindicativos. De ahí la simultaneidad de asociaciones feministas que, en el caso del movimiento argentino, por su dimensión, fue una de sus facetas más notorias.

\section{REFLEXIONES FINALES}

Las "redes intelectuales" que fue forjando Paulina Luisi a lo largo de su militancia feminista internacional fueron varias y complejas. Prueba de ello son los cientos de cartas que contiene su archivo personal; muchas son de mujeres universitarias, médicas sobre todo, con las cuales compartía su interés por los temas vinculados a la higiene social, a la abolición de la prostitución y a la trata de mujeres. El ambiente femenino atraído por temas ajenos al ámbito del hogar era acotado y esto incidía en los encuentros trasnacionales, en la celebración de conferencias de extranjeras, en la asistencia a congresos y en la relación epistolar con mujeres de distintas nacionalidades. Estas conexiones permitían el intercambio de ideas, facilitaban el acceso a información -sobre todo para quienes estaban más alejadas de los centros de producción y de debate feminista- y motivaban la proyección de planes y programas de acción conjunta que pudieran atravesar las fronteras estatales en un plano de relativa horizontalidad. Por ello, son vínculos que trascienden el plano de lo personal, conformando una "red", pues están inmersos en un entramado mayor de relaciones.

El estudio de las redes académicas de Luisi -o más bien su identificación- revela que la década de 1910 fue la más intensa en cuanto a sus vínculos con la Argentina. A través de su acercamiento al asociacionismo feminista de la orilla vecina, Luisi se interiorizó de aquellas problemá- 
ticas femeninas que marcarán su carrera profesional y feminista. Este acercamiento le permitió llevar a cabo iniciativas similares, con mayor éxito en Uruguay porque contó con la experiencia de sus pares argentinas y el hecho de que los procesos políticos de ambos países presentaron diferencias que incidieron en las estrategias de acción pública desarrolladas por los movimientos feministas respectivos. De todas maneras, no parece que las fronteras estatales estuviesen muy marcadas en materia de difusión ideológica y menos aún para las redes feministas de las primeras décadas del siglo XX.

Por último, cabe señalar que el vínculo entre estas mujeres profesionales estuvo cargado de desencuentros y competencias, lo que en ocasiones restó fuerza a la concreción de ciertos objetivos comunes. En la lucha por los derechos políticos y en las estrategias a seguir fue donde más roces se generaron. Se oscilaba entre reproducir prácticas del movimiento sufragista anglosajón y distanciarse asumiendo que las mujeres "latinas" eran diferentes. Asimismo, la política partidaria e ideológica atravesó estos movimientos sufragistas y restó fuerza a la causa. En este sentido, resulta pertinente recordar las palabras de Sara Ahmed en Vivir una vida feminista:

Las historias feministas son historias de las dificultades de ese nosotras, una historia de quienes han tenido que luchar para ser parte de un colectivo feminista, o incluso han tenido luchar en contra de un colectivo feminista para defender una causa feminista (15).

\section{BibLIOGRAFÍA}

Ahmed, Sara. Vivir una vida feminista, Barcelona, Edicions Bellaterra, 2018.

Barrán, José Pedro. Amor y transgresión en Montevideo, 1919-1931, Montevideo, Ediciones de la Banda Oriental, 2001.

Barrancos, Dora. "Julieta Lanteri o la tozudez por la inclusión”, en Inclusión/Exclusión. Historia con mujeres. Dora Barrancos, México/ Buenos Aires, FCE, 2002, pp. 47-76. 
Barry, Carolina. Sufragio femenino. Prácticas y debates politicos, religiosos y culturales en Argentina y América, Buenos Aires, Eduntref, 2011.

Biblioteca Nacional del Uruguay, Archivo Literario (BNAL), Fondo Paulina Luisi

(FPL) Correspondencia personal, manuscritos, fotografías e impresos varios.

Charle, Christophe, Jürgen Schriewer y Peter Wagner (comp.). Redes intelectuales transnacionales: formas de conocimiento académico y buisqueda de identidades culturales, Barcelona, Ediciones Pomares, 2006.

Cuadro Cawen, Inés. Feminismos en el Uruguay del Novecientos. Internacionalismos, culturas políticas e identidades de género (1906-1932). Montevideo, Ediciones de la Banda Oriental-Asociación Uruguaya de Historiadores, 2018.

Devés-Valdés, Eduardo. Redes intelectuales en América Latina. Hacia la constitución de una comunidad intelectual, Santiago, Universidad de Santiago de Chile, 2007.

Dubois, Ellen Carol y Katie Oliviero. "Circling the globe: International feminism reconsidered, 1920 to 1975 ". Women's Studies International Forum $\mathrm{N}^{\circ} 32$, 2009, pp. 1-3.

Ehrick, Christine. "Madrinas and Missionaries: Uruguay and the Pan-American Women's Movement”, Gender \& History, vol.10, N ${ }^{\circ}$ 3, 1998, pp. 406-424.

Guy, Donna, La mujer y la construcción del Estado de Bienestar. Caridady creación de derechos en Argentin. Buenos Aires, Prometeo libros, 2011.

LAgARde, MarCELA. "Enemistad y sororidad: hacia una nueva cultura feminista”. e-mujeres.net. Web. Disponible en: https:/e-mujeres.net/ wp-content/uploads/2016/08/Enemistad-y-sororidad.pdf

. "Sororidad". Diccionario de estudio de género y feminismos. Susana Gamba (coord.). Buenos Aires, Editorial Biblos, 2007, pp. 305-311.

Lavrin, Asunción. "Cambiando actitudes sobre el rol de la mujer: experiencia de los países del cono sur a principios de siglo", European Review of Latin American and Caribbean Studies / Revista Europea de Estudios Latinoamericanos y del Caribe, No. 62, 1997, pp. 71-92. 
'International Feminisms: Latin American Alternatives'. Gender \& History, vol. 10, N³, 1998, pp. 519-534.

Leys Stepan, Nancy. The Hour of Eugenics: Race, Gender, and Nation in Latin America. Ithaca, Cornell University Press, 1991.

López, Gladys. Alicia Moreau de Justo: pionera del feminismo y la igualdad. Buenos Aires, Capital Intelectual, 2008.

López, Sara. El legado de las hermanas Luisi, cien años después. Montevideo, Facultad de Humanidades y Ciencia de la Educación (UdelaR), 2013.

Luisi, Paulina. Movimiento sufragista. Montevideo, El siglo ilustrado, 1919. libre, 1920.

Una moral única para ambos sexos. Buenos Aires, Tribuna - "Conclusiones del trabajo presentado en el Segundo Congreso Americano del

Niño, celebrado en Montevideo el 18 al 25 de mayo de 1919”. Acción Femenina, Montevideo, junio de 1919.

. "A las mujeres de Colombia". La Pluma, enero de 1931, pp. 28-31.

Marpons, Josefina. Paulina Luisi: Una personalidad brillante y singular. Buenos Aires, Torfano, 1950.

Marino, Katherine. Feminism for the Americas: the making of an international human rights movement. North Carolina, University of North Carolina Press, 2019.

Miller, Francesca. “Feminisms and Transnationalism”. Gender \& History, vol. 10, $\mathrm{N}^{\circ} 3,1998$, pp. 569-580.

- "The International Relations of Women of the Americas 1890-1928". The Americas, vol. 43, No 2, 1986, pp. 171-182.

Miranda, Marisa y Gustavo Vallejo (eds.). Una historia de la Eugenesia. Argentina y las redes biopoliticas internacionales, 1912-1945. Buenos Aires, Editorial Biblos, 2012.

Miyares, Alicia. Democracia Feminista. Madrid, Cátedra, 2003.

NARI, Marcela. "El feminismo frente a la cuestión de la mujer en las primeras décadas del siglo XX”. La cuestión social en Argentina 18701943. Juan Suriano (comp.), Buenos Aires, Editorial La Colmena, 2000, pp. 277-300. 
Peluffo, Ana. "Afectos epistolares y sociabilidades en red: Mercedes Cabello de Carbonera y Pedro Pablo de Figueroa". Revista Landa, vol. 6, N², 2018, pp. 140-160.

Rupp, LeILA. Worlds of Women: The Making of an International Women's Movement, Nueva Jersey, Princeton University Press, 1997.

Sapriza, Graciela. "Ciencia, política y reforma social. Esperanza y conflictos de la primera médica del Uruguay: Paulina Luisi (18751950)". Género y ciencia en América Latina: mujeres en la academia y en la clínica (siglos XIX-XX). Jacinto, L. y E. Scarzanella (eds.), Madrid, Estudios AHILA, Iberoamericana, 2011, pp. 53-76.

. "La hora de la Eugenesia, las feministas en la encrucijada". Historia de las mujeres en España y América Latina. Tomo III. Isabel Morant (ed.), Barcelona, Cátedra, 2006, pp. 889-914.

. Memorias de Rebeldía. Siete historias de vida. Montevideo, GRECMU/Puntosur, 1988.

Scarone, Arturo. "Luisi (Paulina)". Uruguayos contemporáneos. Nuevo diccionario de datos biográficos y bibliográficos. Montevideo, Casa A. Barreiro y Ramos, 1948, pp. 284-288.

Vignoli, Marcela. "El Consejo Nacional de Mujeres en Argentina y su dimensión internacional 1900-1910". Travesía, vol. 20, № 2, 2018, pp. 121-147.

Recepción: 15-01-21

Aceptación: 22-06-21 